\title{
Críticas a la propuesta habermasiana de una racionalidad postsecular*
}

\author{
Critiques to the Habermasian Proposal of a \\ Post-Secular Rationlality
}

\author{
Camilo Andrés Garzón Martínez** \\ Catalina Hidalgo Nieto***
}

Recibido: 1 de septiembre de 2016

Aprobado: 12 de diciembre de 2016

Publicado en línea: 10 de octubre de 2017

\section{Resumen}

El artículo se propone evaluar la propuesta normativa de Jürgen Habermas sobre lo que él ha denominado, de manera influyente, la sociedad postsecular. A través de una revisión del debate más general sobre cómo algunos autores ubican la religión en la esfera pública, el artículo propone, primero, una exposición sobre qué es a lo que nos referimos cuando hablamos de una sociedad postsecular. Segundo, profundiza en la propuesta normativa habermasiana para pasar a presentar algunas críticas que se le han hecho a su postura, añadiendo una crítica adicional que parte desde los aportes e intuiciones del diálogo intercultural. El artículo concluye reconociendo

\section{Abstract}

The article evaluates Habermas's proposal of a Post-Secular society. Through a revision of the debate on how some authors place religion in the public sphere, the article, first, offers an outlining about what we mean when we refer to a Post-Secular society. Secondly, it explains Habermas's normative proposal, and presents some critiques made to his view, including a possible new objection in the view of intercultural dialogue. The article concludes by recognizing the importance of an argument that avoids the scenario of both incommensurability and conflict, but it also makes use of some critiques made to Habermas' position to point out that

doi:10.11144/Javeriana.papo22-2.cphr

\footnotetext{
* Artículo de reflexión. Este artículo es producto del proyecto de investigación Religión y racionalidad en la sociedad postsecular, subproyecto Transformaciones de las relaciones entre religión y política en las sociedades actuales, dirigido por el profesor Carlos Miguel Gómez y financiado por Colciencias.

** Internacionalista y politólogo por la Universidad del Rosario y magíster en Estudios Sociales de la Ciencia por la Universidad Nacional de Colombia. Investigador del Centro de Estudios Teológicos y de las Religiones de la Universidad del Rosario. Correo electrónico: camiloandresgarzon@gmail.com ORCID: http://orcid. org/0000-0003-2003-6804

*** Profesional en Filosofía por la Universidad del Rosario y maestranda en Filosofía. Investigadora del Centro de Estudios Teológicos y de las Religiones de la Universidad del Rosario. Correo electrónico: catalina.hidalgo27@ gmail.com ORCID: http://orcid.org/0000-0003-4273-0186
} 
la importancia de una argumentación que no se resigne a la inconmensurabilidad o el conflicto entre los argumentos religiosos y seculares, pero recoge objeciones a la postura habermasiana tanto de la cosecha de algunos de sus críticos como del diálogo intercultural, para señalar que esta, al exigir la traducción de los argumentos a un ámbito neutral del intercambio argumentativo, no responde satisfactoriamente a los escenarios y problemas inherentes al creciente pluralismo de las sociedades contemporáneas.

\section{Palabras clave}

Jürgen Habermas; sociedad postsecular; religion; crítica; diálogo intercultural; esfera pública

\section{Cómo citar este artículo:}

Garzón, C. A. y Hidalgo, C. (2017). Críticas a la propuesta habermasiana de una racionalidad postsecular. Papel Político, 22(2), 427-449. https://doi.org/10.11144/Javeriana. papo22-2.cphr demanding a translation of arguments to a neutral public space does not satisfactorily help to solve many problems or scenarios typical of the growing pluralism of contemporary societies.

\section{Keyworks}

Jürgen Habermas, post-secular society; religion; critique; intercultural dialogue; public sphere. 


\section{¿Qué es una sociedad postsecular?}

Una de las ideas políticas más influyentes que se le ha indilgado a la tradición del pensamiento occidental moderno es que la religión no debe dictar los destinos de la vida política de las sociedades. La afirmación, por supuesto, contraviene la estrecha relación entre religión y política que el Occidente cristiano tuvo en sendos momentos de su desarrollo histórico, y no se puede comprender plenamente si no se atiende a las elucubraciones intelectuales gestadas en torno a los escenarios bélicos que las diferencias religiosas de la Europa del siglo XVI suscitaron en todo el continente.

Estas respuestas intelectuales, presentes seminalmente en Locke y los ilustrados franceses, remitieron, se dice, a la necesidad de separar la Iglesia del Estado para defender un espacio público libre de la influencia de argumentos religiosos. Así es como la formación de los Estados modernos ha sido descrita como un proceso de secularización, entendido, en un primer momento, como la separación del Estado y la Iglesia. Una respuesta que se mostró viable y adecuada para hacer frente a las guerras confesionales de la modernidad temprana.

Como consecuencia de esta idea, se hizo cada vez más patente que el cristianismo, y particularmente en el caso de la primera fase de la secularización europea el catolicismo romano (Mardones, 2005, p. 15), perdía el monopolio cosmovisional que tenía sobre las sociedades, no solo en cuestiones políticas, sino en las respuestas que ofrecía en asuntos relacionados con la naturaleza y la historia, los cuales comenzaron a ser contestados por los desarrollos científicos de la época. Así pues, a diferencia de lo que podría caracterizarse como sociedades preseculares, en las cuales los miembros de la sociedad comparten una visión de mundo unificada por una cosmovisión religiosa y donde no hay una separación tajante entre actividades propiamente religiosas y actividades desprovistas de su referencia, las sociedades modernas experimentan una pluralización de cosmovisiones. En ellas, comparten el mismo escenario social diversas visiones de mundo, y ninguna religión, cosmovisión o incluso ideología laica puede pretender sin contestación ofrecer el punto de vista total y absoluto o el camino exclusivo de realización humana (Gómez, 2014, pp. 27-28). Así pues, una segunda dimensión de lo que se entiende por secularización aparece aquí, ya no en un sentido político, sino social, como quiebre de la unidad cosmovisional.

Asimismo, este escenario de ruptura del monopolio cosmovisional por parte de la religión obliga a que el individuo tenga que moverse entre diferentes esferas autónomas de sentido, cada una de las cuales funciona con una racionalidad más o menos independiente, por lo cual debe asumir la tarea de construir su identidad personal y su sistema de sentido como una labor esencialmente personal y privada. De esta forma, el individuo, no solo elige entre distintas ofertas de sentido, sino que dentro de cada una de ellas halla los elementos que le resultan más significativos y fabrica su propio sistema de sentido (p. 31). Tal condición de la elección individual es un tercer sentido en el que 
se puede entender la secularización, y supone una subjetivización de las condiciones de plausibilidad de la creencia religiosa.

Estas tres dimensiones del proceso de secularización sirvieron de base a las hipótesis de las teorías de la secularización de las décadas de 1970 y 1980, que estipulaban que habría una relación directamente proporcional entre el aumento progresivo de la modernización y la individualización y el desvanecimiento de la religión en la esfera pública. La situación de las sociedades occidentales contemporáneas, sin embargo, no confirma esta relación. Por el contrario, una panorámica de las condiciones sociopolíticas de muchas de estas nos enfrenta ante la evidencia de que las religiones desempeñan un papel fundamental en las sociedades modernas, siendo un factor central en la formación de visiones de mundo y proyectos de vida.

Así pues, esta transformación de las sociedades modernas pone en duda una relación inversamente proporcional entre religión y modernidad y, en especial, el lugar que se le ha conferido basado en la narración de la separación entre religión y política que se presume de la naciente modernidad en la primera mitad del siglo XVI. En el mundo contemporáneo, la influencia religiosa y su relevancia significativa ha trascendido las fronteras de la esfera privada y ha puesto en duda la certeza secularista de que la religión desaparecería de la esfera pública.

Esa nueva situación de la creencia en el mundo moderno ha dado inicio a nuevas formas de nombrar la relación entre la religión y la sociedad. Berger, otrora uno de los proponentes de la teoría de la secularización, se refiere a este fenómeno como la "desecularización del mundo" (1999, p. 1). Pero, sin duda, y por el prestigio acendrado de su pluma, el término acuñado con mayor influencia para referirse a esta situación fue definido por Jürgen Habermas quien se refirió a estas sociedades de interpelación entre religión y secularismo como sociedades postseculares. Con este concepto, Jürgen Habermas ha ejercido una influencia mayor en el reciente debate respecto del rol social y la importancia de la religión. En principio, se trata de un término que busca describir la situación de la religión en buena parte de las sociedades modernas actuales, pero en su centro está la pregunta por la relación entre fe y razón y por la relación entre ciudadanos seculares y religiosos.

¿Qué significa, entonces, que una sociedad sea postsecular? ¿Y en qué sentido no es ya una sociedad meramente secular en las tres dimensiones mencionadas? Habermas nos explica que una sociedad postsecular debe en algún momento de su historia haber pasado por un periodo "secular" (2008, p. 169). No se trata, pues, de un retorno a formas de vida contraseculares, antiseculares o preseculares. Las sociedades postseculares han desarrollado históricamente un conjunto de instituciones seculares, en las cuales se corrobora una división de esferas y una separación paulatina del Estado y la religión. Sin embargo, con todo y esto, ello no deviene inmediatamente un retroceso de lo religioso en el sentido pretendido de la secularización. Como bien afirma Habermas, 
hoy la conciencia pública en Europa puede describirse desde el punto de vista de una "sociedad postsecular", hasta tal punto que en el presente aún debe ajustarse a la existencia continua de comunidades religiosas en un medio cada vez más secularizado. La interpretación revisada de la hipótesis de la secularización se relaciona menos con su fundamento y más con las predicciones acerca del rol futuro de la "religión" (p. 172).

Un análisis detallado de casos particulares de comunidades políticas, como los Estados Unidos, muestra cómo, a pesar de aparecer en la cabecera de procesos múltiples de modernización, cuenta aún con la vitalidad de sus comunidades religiosas y una proporción relativamente invariable de ciudadanos comprometidos con la religión. Si bien el caso se tuvo por mucho tiempo como la gran excepción a la tendencia secularizante, hoy, sin embargo, los Estados Unidos muestran que hay múltiples secularizaciones, y que en cada una de ellas la relación entre religión y modernidad es compleja, y en ningún caso solo excluyente (p. 171).

Pero por encima de los casos particulares que refutan los supuestos de la secularización, Habermas menciona, sobre todo, tres fenómenos entrecruzados que convergen para crear la impresión de que estamos ante sociedades postseculares: 1) la expansión misionera, 2) la radicalización fundamentalista y 3) la instrumentalización política del potencial para la violencia, innato en muchas de las religiones del mundo (p. 170). Primeo, porque los grupos ortodoxos, o al menos conservadores dentro de las organizaciones religiosas y las Iglesias establecidas, están desarrollándose por todas partes, y creciendo sus adeptos, sobre todo en África y América Latina. Segundo, porque entre los grupos de mayor crecimiento se cuentan aquellos que pueden describirse como "fundamentalistas" en el sentido que combaten el mundo moderno o se apartan de él, aislándose. Y tercero, porque entre quienes enfrentan el mundo moderno, se cuenta el régimen gullah en Irán o el terrorismo islámico, que son ejemplos del potencial de desencadenamiento violento que tiene la religión al participar de conflictos que en su origen son profanos (p. 171).

Acompaña su argumentación Habermas señalando que la percepción extendida acerca de conflictos globales que se presentan con frecuencia como dependientes de la lucha religiosa cambia la conciencia pública. La mayoría de los ciudadanos no requiere ni siquiera la presencia de movimientos fundamentalistas intrusivos, ni el miedo al terrorismo (definido en términos religiosos), para hacerse consciente de su propia relatividad respecto del horizonte global (p. 172). El horizonte de percepción de los ciudadanos globales muestra cómo sus comunidades políticas se ven en la encrucijada de debates de orden internacional que amenazan su propia supervivencia y, que muchas veces, como lo constata brutalmente la sociedad norteamericana la mañana del 11 de septiembre de 2001, se refieren a móviles religiosos. Este cambio, no solo se produce en el ámbito internacional, sino que ocurre también dentro de las esferas públicas nacionales en las discusiones públicas: 
Estoy pensando aquí en el hecho de que las iglesias y las organizaciones religiosas están asumiendo cada vez más el rol de "comunidades de interpretación” en la arena pública de las sociedades seculares, y pueden así conseguir influencia en la opinión pública y en la formación del albedrío de los ciudadanos. (p. 173)

La aproximación de Habermas al describir la importancia religiosa en la sociedad postsecular parece indicar que su lectura hacía el rol de la religión tiende a verla como una amenaza al orden civil y un potencial detonante de violencia o, al menos, de conflictos. Retener esto es importante, porque nos permite entender, en el acápite siguiente, el rol que está dispuesto a dar a los argumentos religiosos y cómo ello es criticable en la medida en que les asigna una función que no necesariamente es común a todo tipo de argumento religioso.

En resumen, se cierne un desafío sobre las sociedades postseculares, pues, no siendo ya cierto que los argumentos religiosos están excluidos del debate público, y que la exclusión de estos supondría un revés de los principios de igualdad de participación de todos los ciudadanos, debe dárseles un lugar junto con los argumentos seculares. ¿Cómo, entonces, responder pluralistamente al desafío de la diversidad de posiciones entre ciudadanos religiosos y seculares en el seno del debate público? Se ve cómo para Habermas la comprensión adecuada de la situación de la religión implica tanto una dimensión descriptiva, orientada a representar las formas como la religión se presenta en su encuentro con la modernidad, como normativa, enfocada hacia la pregunta por cuál debe ser el papel y el lugar de la religión y de los argumentos religiosos en la sociedad postsecular.

La propuesta normativa de Habermas ofrece una orientación sobre las actuales sociedades postseculares, al plantear una transformación de las relaciones entre religión y racionalidad. A continuación, expondremos el lado normativo de la propuesta habermasiana para una sociedad postsecular.

\section{La propuesta normativa habermasiana de una sociedad postsecular}

Dentro de las discusiones académicas suscitadas en torno a esta nueva coyuntura de interpelación entre la religión y la política en las sociedades contemporáneas, han surgido dos posiciones que buscan darles un lugar a aquellos argumentos de origen religioso y ser escuchados en los procesos de toma de decisión que acaecen en la esfera pública. Mientras que, por un lado, autores como Robert Audi representan el punto de vista liberal que defiende una postura exclusivista, otros autores como Nicholas Wolterstorff se basan en una posición teológicamente orientada para defender una propuesta inclusivista.

Como bien lo indica su nombre, la postura exclusivista adopta como premisa principal la neutralidad del Estado frente a la religión, pues considera que este es el único modo en el cual se puede garantizar la protección de la libertad religiosa en cuanto evita 
cualquier trato preferencial del Estado hacia cualquier grupo o tradición religiosa. Sin embargo, la defensa de la separación entre Estado e Iglesia no implica la eliminación de toda posibilidad de comunicación. Al contrario, los defensores de esta postura consideran que, a la manera de Rawls, puede haber un tipo de overlap entre obligaciones cimentadas en fuentes religiosas y aquellas obligaciones civiles cimentadas en fuentes seculares (Audi y Wolterstorff, 1997, p. 14). Pero, para que este tipo de colaboración recíproca entre obligaciones religiosas y obligaciones civiles tenga lugar, "la cooperación mutua debe converger en un punto secular" (p. 143), el cual termina por imponerles ciertas obligaciones a los ciudadanos religiosos, como el deber de comprenderse a sí mismos en términos seculares. Esto es así, pues, para Audi, "los ciudadanos están en la obligación prima facie de ofrecer por lo menos una razón secular ${ }^{1}$ que sea evidentemente adecuada y lo suficientemente motivante" (p. 123).

Por su parte, la postura inclusivista es crítica con respecto a la postura liberal y a su restricción de las razones religiosas ${ }^{2}$ en el debate público, pues considera que esta restricción, antes de ser una garantía de la libertad religiosa, es una violación de esta (p. 77). Para autores como Wolterstorff, el ejercicio de la ciudadanía no puede incluir una restricción al uso de razones religiosas en la esfera pública, ni mucho menos puede exigir apelar a fuentes independientes. El problema con este tipo de exigencias es que para la mayoría de los ciudadanos religiosos su existencia política depende de la religión que practican, de modo que les resulta imposible apelar a una fuente independiente en el momento de defender el tipo de demandas que presentan en la esfera pública. Para Wolterstorff, esta fuente independiente sencillamente no existe. En efecto, la postura inclusivista pone en duda la existencia de eso que Rawls denominó "una cultura política compartida" apoyada en la existencia de una razón pública que se vale de una "fuente independiente". En resumen, para los inclusivistas, "hay que dejar que los ciudadanos usen las razones que ellos consideran apropiadas" (p. 113). Esto no implica el establecimiento de un "todo vale", pues el mismo Wolterstorff hace énfasis en la necesidad de tres tipos de restricciones que han de ser tenidas en cuenta para estos casos: 1) respeto, 2) actitud de escucha y 3) prohibición de la promoción de intereses personales (pp. 112-113).

Es justamente en medio del debate entre inclusivistas y exclusivistas donde la postura de Jürgen Habermas resulta ser interesante por cuanto intenta darles un lugar en la esfera pública tanto a los argumentos religiosos como a los argumentos seculares. Tomando como punto de partida su análisis descriptivo del lugar de la religión en la

\footnotetext{
${ }^{1}$ Entendida a la manera de Audi y Wolterstorff, a saber, como aquella "razón cuya fuerza normativa o elemento justificatorio no depende de la existencia de Dios ni de ciertas consideraciones teológicas, ni del pronunciamiento de una persona o institución consideradas como autoridad religiosa" (1997, p. 26).

${ }^{2}$ Entendiendo estas últimas en el sentido que les da Rummers, quien invierte la definición presentada por Audi de las razones seculares. Así, una razón religiosa es aquella cuya fuerza justificatoria está basada en algún tipo de fuente o autoridad religiosa (Rummers, 2010, p. 287).
} 
sociedad contemporánea, que hemos presentado previamente, Habermas ofrece una propuesta normativa encaminada a señalar el lugar y la función que han de cumplir en la esfera pública tanto los argumentos religiosos como los argumentos seculares.

Habermas utiliza el término sociedad postsecular para caracterizar a la sociedad contemporánea, porque ello le permite hacer énfasis en la relación de aprendizaje colaborativo que debe existir entre ciudadanos religiosos y no religiosos. Su propuesta parte de señalar la necesidad de un cambio de conciencia que invite a ciudadanos religiosos y seculares a adaptarse a la existencia de comunidades religiosas en un entorno que pretende ser cada vez más secularizado (2006a, p. 5).

Una sociedad postsecular es, entonces, en un sentido normativo, aquella en la cual sus ciudadanos, en cuanto sujetos capaces de lenguaje y acción, son capaces de ponerse de acuerdo para establecer las condiciones de posibilidad de una sociedad inclusiva y mutuamente colaborativa. La dificultad radica en que en las sociedades contemporáneas pluralistas no todos los ciudadanos apelan a las mismas fuentes de justificación en el momento de ofrecer argumentos durante las prácticas comunicativas que acontecen en la esfera pública. Y ante el "resurgimiento" de la religión en las actuales sociedades, la relación entre argumentos seculares y argumentos religiosos hace que el concepto de postsecular surja como una respuesta a la persistencia de la religión en un escenario secular, lo cual implica un llamado a todos los ciudadanos para que lleven a cabo un cambio de actitud que les permita vivir, por un lado, con las consecuencias secularizantes producidas por la separación de esferas y por la expansión de las imágenes naturalistas del mundo; y por el otro, con la inesperada revitalización y politización de las comunidades y tradiciones religiosas (Habermas, 2006a, p. 9).

Al llevar a cabo este diagnóstico, la preocupación de Habermas va más allá de aquella que inquietó a los padres de la teoría crítica, pues, para él, el ejercicio crítico-teórico no puede encaminarse solo hacia una mejor comprensión de la realidad y sus cambios sociopolíticos, sino que debe estar encaminado hacia la creación de las condiciones políticas y sociales que conduzcan a una sociedad civil inclusiva, en la que "tanto la ciudadanía en igualdad de condiciones, como las diferencias procedentes de culturas diversas se complementen de manera correcta” (p. 10). Por eso, Habermas busca fundamentar normativamente aquellas sociedades en las cuales el resurgimiento de la religión y los esfuerzos secularistas salen al encuentro en la esfera pública.

Habermas promueve una esfera pública postsecular, en la cual tenga lugar un aprendizaje colaborativo entre ciudadanos religiosos y ciudadanos seculares basado en un reconocimiento recíproco que les permita estar dispuestos a escucharse mutuamente y a aprender los unos de los otros en los debates públicos (p. 11). En contraste con los exclusionistas, Habermas está seguro de que puede sacarse provecho de lo que él ha denominado el "potencial semántico de las religiones", i. e., de los contenidos semánticos, 
los significados inspiradores que solo se encuentran en las tradiciones religiosas y que albergan una fuerza especial para articular asuntos fundamentales para la convivencia humana. Sin embargo, por cuanto una sociedad postsecular sigue siendo secular, en el sentido de que debe ser compatible con la idea de un Estado neutral que no favorezca ninguna tradición religiosa para así posibilitar un pluralismo religioso pacífico, Habermas se ocupa de analizar cómo puede sacarse provecho de esos potenciales semánticos de las religiones en los debates públicos y cómo ha de tener lugar ese aprendizaje mutuamente colaborativo entre ciudadanos religiosos y ciudadanos seculares.

El escenario en el cual ocurre este aprendizaje colaborativo es la práctica comunicativa de intercambio de razones, la cual se constituye en un punto de partida para el establecimiento de un espacio de deliberación donde la razón secular y la conciencia religiosa puedan encontrarse de manera complementaria. El lugar de las prácticas comunicativas dentro de la propuesta de Habermas resulta fundamental en todo su desarrollo teóriconormativo, pues es en ellas donde ocurre la elaboración de los presupuestos normativos de las sociedades postseculares. Para argumentar a favor de la importancia de las prácticas comunicativas, Habermas parte de una perspectiva histórico-contextual y afirma que todos los grupos humanos "comparten una forma de vida comunicativa y estructurada mediante el entendimiento lingüístico" (1991, p. 70). Es decir que la argumentación, aquel proceso mismo de dar y examinar razones mediante lo que puede ser una actividad regulada de manera comunicativa, es una práctica social común a todas las culturas y sociedades.

Establecido este presupuesto, vale la pena señalar cuál es el tipo de racionalidad propio de esas prácticas comunicativas. Si bien es cierto que Habermas habla de una "racionalidad cognitivo-instrumental", en la cual se hace un uso no comunicativo de un saber, por ejemplo aquellos saberes utilizados en acciones teleológicas, la racionalidad propia de las prácticas comunicativas es una "racionalidad comunicativa", en la cual el empleo comunicativo de un saber tiene lugar en un escenario de discusión y deliberación entre los miembros de una sociedad (2010b, pp. 33-35), quienes se reúnen ante la necesidad de solucionar desacuerdos producidos por la pluralidad de cosmovisiones y de esferas de sentido de las actuales sociedades pluralistas. La racionalidad comunicativa está orientada hacia un horizonte de entendimiento mutuo que descansa en una teoría pragmática del significado, según la cual el significado de una proposición no descansa en sus condiciones de verdad, sino en las prácticas comunicativas, esto es, en un contexto comunicativo mucho más amplio que implica las intenciones de los hablantes, la situación del habla, el empleo del lenguaje, los contextos de ese empleo y las pretensiones y toma de postura de los hablantes.

De modo que para Habermas en el escenario público es donde se despliega la evaluación intersubjetiva de los argumentos ofrecidos por cada uno de los participantes de las prácticas comunicativas. Y puesto que estas consisten en un intercambio de argumentos, 
es justamente acá donde la dimensión argumentativa desempeña un papel fundamental en el momento de evaluar qué argumento es mejor que otro. Para Habermas, hablar implica siempre generar pretensiones de validez contenidas en los actos de habla de los interlocutores. Estas generan un compromiso con aquello que se está enunciando en cuanto deben satisfacer el requisito esencial de la racionalidad comunicativa: "deben ser susceptibles de fundamentación y de crítica" (p. 40). En otras palabras, los participantes en una práctica comunicativa deben estar en la capacidad de ofrecer las razones que fundamentan sus pretensiones de validez y, al mismo tiempo, deben estar dispuestos a escuchar aquellas críticas que conduzcan a la discusión hacia la instauración de un intercambio de razones.

Ahora bien, en cuanto la práctica de la argumentación, es una actividad orientada por reglas, los participantes se comprometen también con una serie de presuposiciones que hacen la práctica posible. Para Habermas, las cuatro principales presuposiciones pragmáticas de la argumentación son:

a) Carácter público e inclusión: no puede excluirse a nadie que, en relación con la pretensión de validez controvertida, pueda hacer un aporte relevante; b) igualdad en el ejercicio de las facultades de comunicación: a todos se les conceden las mismas oportunidades para expresarse sobre la materia; c) exclusión del engaño y la ilusión: los participantes deben creer lo que dicen; d) carencia de coacciones: la comunicación debe estar libre de restricciones, ya que estas evitan que el mejor argumento pueda salir a la luz y predeterminan el resultado de la discusión. (Habermas, 2006a, p. 57)

La importancia de estas presuposiciones yace en que funcionan como unos presupuestos regulativos que, además de que son operativamente eficaces en la regulación del comportamiento de los participantes de la argumentación, permiten evaluar las prácticas comunicativas. En cuanto principios contrafácticos, no se trata de que estos presupuestos pragmáticos describan el modo como ocurren de facto las prácticas comunicativas, sino más bien sirven como ideas regulativas de la discusión.

Sentado este panorama relacionado con la importancia de la práctica comunicativa y con el papel que en ella cumple la dimensión argumentativa, ¿̇cuál es el lugar que Habermas le da en la argumentación al intercambio de razones entre ciudadanos religiosos y seculares? Por cuanto este intercambio de razones ha de ocurrir en una discusión pública, Habermas señala ciertas obligaciones que han de ser satisfechas por los ciudadanos religiosos y no religiosos. Estas obligaciones pueden ser caracterizadas en dos dimensiones: por un lado, la dimensión ética, y por otro, la dimensión epistémica.

Con respecto a la primera, Habermas, como buen demócrata, está preocupado por los lazos de solidaridad que resultan ser fundamentales para el mantenimiento de la cohesión social de un Estado democrático. Se trata de esas expectativas relativas a un 
comportamiento cívico, al reconocimiento mutuo y a la tolerancia que debe existir entre conciudadanos. Así como los ciudadanos seculares esperan que las instituciones estatales tomen en cuenta sus demandas, los ciudadanos religiosos también esperan que tanto las instituciones estatales como sus conciudadanos seculares tomen en serio las suyas. Para que esto ocurra, es necesario "hacer plausible desde una perspectiva secular, la hipótesis de que las tradiciones religiosas no son ni irracionales ni absurdas, [...] de que pueden albergar intuiciones racionales y elementos de lo que cabe aprender" (p. 13). Sin embargo, para que la dimensión ética de las obligaciones que una sociedad postsecular les impone tanto a ciudadanos religiosos como a ciudadanos seculares sea posible, es necesario que ambas partes cumplan con ciertas obligaciones epistémicas que se siguen de la exigencia misma de respetarse mutuamente.

La dimensión epistémica de dichas obligaciones exige ciertas actitudes cognitivas que deben ser seguidas, respectivamente, por los ciudadanos religiosos y los ciudadanos seculares. Según Habermas, son tres las exigencias epistémicas que una sociedad postsecular plantea para los ciudadanos religiosos:

i) deben haber aprendido a poner las convicciones de su propia tradición en una relación reflexiva y lúcida con el hecho del pluralismo de religiones y cosmovisiones; ii) deben haber armonizado su fe con el privilegio epistemológico de las ciencias socialmente institucionalizadas, iii) deben comprometerse con el primado del Estado laico, y con la moral universalista de la sociedad. (p. 12)

De modo que, en un primer momento, se les está exigiendo a los ciudadanos religiosos que reflexionen sobre el lugar que tiene su tradición en una sociedad pluralista, que reconozcan la autoridad de las ciencias y otros saberes producto del naturalismo cientificista y que, además, se comprometan con los principios éticos y políticos seculares. Pero estas exigencias por sí solas no garantizan la inclusión de argumentos religiosos en la esfera pública. Es justamente acá donde, en contraste con los inclusionistas, Habermas afirma que la inclusión de los argumentos religiosos en la esfera pública debe darse mediante un lenguaje universalmente accesible a todos (Rummers, 2010, p. 386); solo mediante un lenguaje público y neutral los potenciales semánticos religiosos podrán desplegar su fuerza inspiradora, pues solo así podrán ser transformados en un tipo de habla argumentativa propio de la esfera pública.

Los ciudadanos religiosos deben estar en la capacidad de traducir sus demandas a un lenguaje públicamente accesible, pero ċcómo lograr esa traducción? Lejos de querer plantear un tipo de traducción encaminada a la búsqueda de equivalentes conceptuales de un lenguaje a otro, el objetivo es crear un lenguaje secular a partir del lenguaje religioso que rescate el potencial normativo del segundo, pero, al mismo tiempo, desligándolo de toda 
referencia a una tradición religiosa. Al respecto, Habermas cita el concepto de dignidad humana que es una secularización de la idea cristiana de que el ser humano es creado a imagen y semejanza de Dios y el concepto de autonomía que deriva a partir del concepto de libre albedrío. Solo así puede garantizarse la instauración de una cultura política pública incluyente donde "las doctrinas comprehensivas - sean o no religiosas - puedan introducirse en la discusión política pública ofreciendo razones apropiadas” (p. 130).

Ahora bien, con respecto a las exigencias impuestas a los ciudadanos seculares, estos deben satisfacer cierta expectativa normativa de abrir sus mentes al posible contenido cognitivo de las contribuciones religiosas, lo cual significa llevar a cabo un proceso de autosuperación de la modernidad exclusivamente entendida en términos secularistas. De manera que los ciudadanos seculares deben, por un lado, trazar un límite entre fe y saber y abstenerse de juzgar peyorativa y polémicamente las verdades religiosas; y por otro, reflexionar críticamente sobre esa razón secular, cuyos presupuestos cientificistas excluyen las doctrinas religiosas con respecto a la genealogía de la razón (p. 146).

No obstante, planteado así el panorama, queda por evaluarse si, en efecto, la propuesta de Habermas estipula las mismas exigencias para ciudadanos religiosos y no religiosos, y hasta qué punto está dispuesto a darles cabida a los argumentos de orden religioso en el espacio público. La siguiente sección expondrá algunas críticas que se le han hecho a la propuesta de Habermas, justamente al preguntarse esto. Con ello, se irá dibujando un camino de crítica hacia las exigencias de la racionalidad postsecular.

\section{Críticas a la propuesta normativa habermasiana de una sociedad postsecular}

La amplia obra de Jürgen Habermas permite constatar que el intento normativo de una sociedad postsecular no siempre estuvo presente en sus trabajos previos. En su seminal Teoría de la acción comunicativa, publicada en 1981, Habermas acude a Max Weber para hablar del desencantamiento del mundo y el desempoderamiento del dominio de lo sagrado, señalándolo como una ganancia inequívoca de la humanidad (Habermas, 2010a, p. 77). Al final de la década, sin embargo, se empieza a ver su consideración de la importancia de la religión como un recurso semántico para la filosofía posmetafísica. En el pasaje que cierra el ensayo “Motivos del pensamiento posmetafísico", Habermas menciona cómo este pensamiento, propio de la filosofía contemporánea, no puede prescindir de la religión, ya que el lenguaje religioso es portador de contenidos inspiradores e indispensables que el lenguaje filosófico en su fuerza explicativa no puede ofrecer (Habermas, 1988, p. 62).

Esta idea del acompañamiento del pensamiento religioso en las otras formas del pensamiento contemporáneo no hace sino adquirir importancia en sus trabajos posteriores, máxime cuando los desafíos que suponen los adelantos de la biotecnología y la avanzada del fundamentalismo religioso en la esfera pública a comienzos del siglo XXI le 
confirman la relevancia de los contenidos del pensamiento religioso en la configuración del hombre y su rol en la política contemporánea. Esta atención a la religión, sin embargo, debe ubicarse dentro de los límites de su proyecto filosófico, proyecto que no busca reemplazar la razón secular por la religiosa, sino darle el debido lugar a esta última en el espacio público. Tiene sentido, entonces, que para Habermas la filosofía posmetafísica no se deba involucrar con cuestiones relacionadas con pretensiones de verdad de las afirmaciones religiosas, sino valerse de los recursos semánticos de la religión, trasladando esos contenidos a un lenguaje neutral. Esa es, pues, la exigencia que hace a los argumentos de los ciudadanos religiosos al participar en la esfera pública postsecular.

Acaso las lecturas más juiciosas respecto de las limitantes de la propuesta de Habermas vengan de los comentarios que ya desde hace una década viene haciendo Cooke (2006, 2007) a su postura postsecular. En un primer momento, afirma Cooke, es cuestionable su intención de no considerar la pretensión de verdad de los argumentos religiosos. Al no asociar los argumentos religiosos a discursos éticos o legales, parece vincular los argumentos religiosos a argumentos de validez estética, en el sentido en que ambos cumplen una función de apertura del mundo aun cuando no son universalizables. Esta identificación de lo religioso con lo estético deja de lado un componente importante del punto de vista creyente, pues las pretensiones de validez religiosas, a diferencia de las pretensiones meramente estéticas, no se ajustan tan fácilmente a la categoría de un argumento no universalizable. Esto porque muchos argumentos religiosos tienen, en efecto, una evidente orientación universal que cree en una verdad que aplica para todos y en cualquier lugar (Cooke, 2007, p. 192). El argumento religioso, en suma, desestabiliza la distinción habermasiana entre pretensiones de validez universalizables y no universalizables.

Otro frente de crítica de la propuesta habermasiana es hasta qué punto ella permite efectivamente la participación de argumentos religiosos. Si bien la propuesta de Habermas busca promover una esfera pública postsecular en la cual tenga lugar un aprendizaje colaborativo entre ciudadanos religiosos y ciudadanos seculares basado en un reconocimiento recíproco, su propuesta solo parece tener en cuenta un aspecto de la esfera pública. Este aspecto, como menciona Cooke (2007, p. 193), hace referencia al ámbito débil de la formación de la sociedad civil; en este ocurre la formación de la opinión y no está definido tan claramente por instituciones. Aquí, reconocer la necesidad de que todos los ciudadanos hablen y sean escuchados no parece algo tan problemático. Empero, la esfera pública no es simplemente un lugar donde entran en interpelación distintas pretensiones de validez, sino que es un lugar donde se toman decisiones. Estas decisiones se llevan a cabo en el ámbito duro de la política, en cuerpos constituidos por la ley, como el Parlamento o las Cortes.

En esta esfera, Habermas ya no puede simplemente exigir a los distintos ciudadanos que se escuchen, sino que tiene que establecer parámetros para la toma de decisiones, y los parámetros en esta instancia ya no son, para él, dictados por argumentos religiosos. 
Es decir que los ciudadanos que forman parte de cuerpos colegiados de toma de decisión requieren formular sus contribuciones a las discusiones en términos seculares. Tanto creyentes como no creyentes han de trasladar los resultados de sus discusiones en la política débil a un lenguaje secular en la política fuerte. Esta desigualdad de valoración de los argumentos de los ciudadanos creyentes y seculares contradice sus pretensiones de darles cabida igualitariamente a ambos o, por lo menos, las limita al ámbito de la formación de la opinión y no les da cabida en el de la toma de decisiones.

De ahí que cuando Habermas nos hable de ejemplos de traducción del lenguaje religioso al lenguaje secular, estos apelen a temas sobre los que difícilmente habría disenso en el ámbito de la política dura, como es el caso de la traducción religiosa del "ser creado a imagen y semejanza de Dios”, que en términos seculares equivale al de dignidad humana. Empero, en temas donde es probable una mayor distancia, como el del aborto o la eutanasia, las valoraciones de la vida entre una y otra perspectiva son más distantes, y no se ve tan claro cómo pueda proceder una traducción. De ahí también que, en ocasiones, el filósofo se refiera a la razonable expectativa de ausencia de consenso que acompaña a los participantes en las deliberaciones en las que las contribuciones religiosas son admitidas, expectativa que contrasta con sus promesas de razonable consenso, que, hasta ahora, ha sido piedra angular de sus ideas sobre la verdad, la moralidad e, incluso, la ley y la democracia (p. 194).

Para Cooke, una consideración más incluyente del punto de vista del creyente debería permitirles a los argumentos religiosos participar en todos los niveles de la deliberación democrática. No solo en la informal de la política débil, sino en la esfera formalmente organizada de la legislación democrática y la toma de decisiones. Ante esto, sabe que la objeción de Habermas es que ceder en este sentido implicaría una ruptura con el principio liberal de la neutralidad estatal ante visiones de mundo en competencia, pero argumenta Cooke que, así como puede aceptar con Habermas el inmenso logro que supuso históricamente llegar a la concreción de un Estado liberal, también sabe que la institucionalización de ese principio fue producto de un proceso histórico de aprendizaje que está abierto y que es susceptible de reinterpretación a la luz de nuevos cambios en la sociedad. Así pues, en su perspectiva, una relectura del principio de la neutralidad estatal no necesariamente implica negar los avances que han resultado de la secularización y de la democratización de la autoridad política. No es entonces un argumento religioso el que pone en riesgo la deliberación en el espacio público, sino un argumento autoritario, a saber, un argumento que niega que el conocimiento de la verdad es dependiente de las prácticas lingüísticas de agentes humanos en contextos históricos y socioculturalmente distintos (p. 199). Este cambio de perspectiva les permitiría a los ciudadanos creyentes un marco de participación mayor, en cuanto queda superado el prejuicio que parece existir en Habermas: asociar los argumentos religiosos con los argumentos autoritarios, asociación que no necesariamente cobija a todo tipo de argumento religioso. 
En la misma línea crítica de las objeciones anteriores, Cooke pone en tela de juicio el hecho de que la inclusión de argumentos religiosos deba darse en un lenguaje universalmente accesible a todos. Más que como una condición para el diálogo, Cooke ve el surgimiento de un lenguaje universalmente accesible a todos como su resultado. En efecto, tal lenguaje sería el resultado de una fusión de horizontes y de la posterior producción de una nueva perspectiva que incluya las demandas y las creencias de las partes involucradas en el diálogo.

Por otra parte, según Cooke, para Habermas la exigencia de la traducción a ese lenguaje universalmente accesible a todos solo puede ser cumplida realmente por los ciudadanos con visiones de mundo posmetafisicas, esto es, ciudadanos comprometidos con una interpretación posmetafísica que no apela a ninguna autoridad religiosa. Sin embargo, el ciudadano religioso difícilmente podrá desprenderse de las justificaciones que recurren al recurso de la autoridad o fuente religiosa. De nuevo, Cooke: "Las justificaciones seculares de las decisiones políticas no son igualmente accesibles a todos los ciudadanos, solo lo son a aquellos suscritos a un pensamiento posmetafísico" (las traducciones son nuestras) (p. 233).

Por esto, la crítica de Cooke a la exigencia de traducción señala lo contradictoria que esta puede ser con respeto a la autonomía política de los ciudadanos religiosos (p. 231), pues, si estos quieren participar en política, deben ser capaces de traducir en términos seculares sus creencias y demandas. De ahí que considere que el debate público no puede ser concebido sobre una idea sustancial de razón pública, esto es, una idea de razón pública secular cuyo lenguaje es universalmente accesible.

Otra de las críticas más agudas a la propuesta habermasiana la hace Rummens (2010). Para Rummens, una crítica a Habermas no implica una refutación completa de su proyecto normativo, antes bien, influido por este, busca seguir contribuyendo a la propuesta de una esfera pública postsecular de deliberación. Así puesto su propósito, para Rummens no se trata de buscar la aceptabilidad general de los argumentos religiosos, sino de investigar la posibilidad de que cierto tipo de argumentos religiosos sean aceptables dependiendo de si son o no compatibles con las prácticas legales y sociales del constitucionalismo democrático (Rummens, 2010, p. 386).

Para plantear esto, Rummens hace una división de tres tipos de argumentos religiosos (argumentos de autonomía, identidad y autoridad) basados en los papeles que esos argumentos desempeñan en el debate. Un ejemplo de argumento de autonomía es un argumento que defienda que todos los seres humanos deben tener un incondicional acceso a medios básicos de subsistencia, cuya justificación esté anclada en pasajes relevantes de la Biblia, que el creyente acepta como canónicos (p. 388).

Otro tipo de argumento es el concerniente a la identidad. Este tipo de argumento combina dos premisas: por una parte, plantea que un adecuado reconocimiento de la 
identidad de los otros requiere que nos ajustemos a prácticas que estén acendradas en su sistema de valores; y por otra, que somos capaces de dar razones que indiquen por qué una específica práctica corresponde realmente a ese sistema de valores. Los argumentos de identidad lo son en cuanto otorgan razones para unir una práctica particular a un sistema de valores. Argumentos como la defensa del reconocimiento de los días festivos para miembros de una comunidad religiosa o del porte de ciertas vestimentas para practicantes de un culto determinado son argumentos que se inscriben aquí.

Por último, los argumentos de autoridad apelan a fuentes reconocidas como legítimas entre los miembros de una comunidad religiosa para imponer sus principios o valores en el conjunto todo de la sociedad. El ejemplo del rechazo de la homosexualidad porque supone un comportamiento pecaminoso en la perspectiva del orden natural y de Dios entra en esta posición. Para Rummens, las dos primeras categorías de argumentos son aceptables en el espacio público, mientras que la última no. Esto porque los argumentos de autoridad "están en contradicción con los requerimientos de imparcialidad y autonomía como presuposiciones constitutivas de una deliberación razonabley, por tanto, cuestionan la legitimidad de la deliberación como fuente de una autoridad política postradicional” (p. 394). Así, Rummens está dispuesto a darles una mayor cabida a los argumentos religiosos en el ámbito público que Habermas, siempre que estos no sean de orden autoritario.

En definitiva, lo que une la crítica de Rummens y de Cooke no es una postura que vuelva sobre las posiciones inclusivistas o exlusionistas de Audi o Wolterstorff para desmontar el proyecto de Habermas. Ambos están de acuerdo en que el camino no puede seguir siendo el de plantear un liberalismo ingenuo, cuyas premisas no permiten el cumplimiento cabal de la igualdad en cuanto excluyen los argumentos de una porción importante de los ciudadanos religiosos. Tampoco la respuesta es apelar al reconocimiento de cualquier postura religiosa en el espacio público, pues hay que limitar también hasta qué punto un argumento religioso puede tener validez para otros y ser comunicada su pretensión de verdad con miras a la comprensión del otro, pero también a la toma de decisiones.

Las críticas más sólidas a Habermas, entonces, no son antiseculares o meramente seculares, son postseculares en cuanto reconocen la validez de la descripción que Habermas hace de la complejidad de argumentaciones que se cierne sobre el panorama sociopolítico de las sociedades contemporáneas. Y lo son también en un sentido más fuerte, incluso, que el del mismo Habermas, pues, si bien comparten con él las exigencias epistémicas que la sociedad postsecular plantea para los ciudadanos religiosos, creen que en su propuesta no les dio suficiente cabida a estos en el ámbito de la toma de decisiones política. De ahí que para Cooke la respuesta de Habermas a una sociedad postsecular siga siendo secular. De lo que se trata, entonces, es de plantear un Estado postsecular para una sociedad que también lo es. Tanto para Cooke como para Rummens, no son los argumentos religiosos los que hay que enfrentar, sino el pensamiento autoritario. 
Estas respuestas a los retos que genera la pluralidad en las sociedades contemporáneas están lejos de resolver las tensiones que pueden existir entre ciudadanos que apelan a razones religiosas y seculares. Pues en el centro de la experiencia religiosa existen convicciones que no pueden ser meramente racionalizables o reducibles al ámbito de la vida privada (p.407), y estas convicciones entrarán en tensión permanentemente con las razones seculares. En ese sentido, la pregunta por las razones válidas en el ámbito público remite a la cuestión más amplia acerca de la posibilidad de la interpelación de razones. Desde entornos socioculturales distintos del europeo, en particular el latinoamericano, por la peculiar presencia de comunidades indígenas en sus territorios, la situación de interpelación entre miembros de una comunidad política no puede verse meramente como un intercambio de razones en una racionalidad compartida y común, como lo presupone Habermas, sino que, en un sentido más radical, lo que allí se interpela son distintas racionalidades. De modo que el intento de diálogo y la comprensión del otro se hace sobre el trasfondo de la ausencia de criterios universalizables de la razón. Aquí se hace patente un vínculo entre dos caminos de reflexión filosófica: la discusión sobre la sociedad postsecular y las propuestas del diálogo intercultural. Tender puentes entre ambas reflexiones hace posible una nueva lectura de la propuesta habermasiana sobre la sociedad postsecular. Una lectura que no renuncia a ser postsecular, pero que sí puede complementar los vacíos de sus movimientos iniciales con el acervo reflexivo de la crítica intercultural.

\section{Una posible crítica a la propuesta de Habermas desde el diálogo intercultural}

El camino hacia el cual conducen las críticas al modelo habermasiano plantea un nuevo desafío propio de las actuales sociedades pluralistas. ¿Pero qué quiere decir realmente esta calificación de pluralismo? Su denominación implica que en estas sociedades hay una diversidad de centros de sentido alrededor de los cuales gravitan numerosas prácticas $\mathrm{y}$ creencias, las cuales responden a una forma de racionalidad propia a cada universo de sentido. Hablar de sociedades pluralistas y sus distintas "formas de racionalidad" implica señalar la existencia de una diversidad de proyectos de vida heterogéneos que están anclados a tradiciones o cosmovisiones que les brindan una fuente de sentido y, por ende, una fuente de justificación a sus prácticas y creencias. Las sociedades pluralistas, al caracterizarse por la existencia de formas de racionalidad heterogéneas, enfrentan una problemática que resulta ser inevitable en contextos de diversidad cultural. Se trata de los conflictos interculturales, aquellos que ocurren cuando dos o más formas de racionalidad se enfrentan ante un asunto que resulta ser de mutua afectación o incumbencia, cuya solución difícilmente puede estar situada en una sola forma de racionalidad o en lo que el mismo Habermas ha llamado un lenguaje neutral. Hablar de neutralidad en las sociedades pluralistas es una quimera que puede esconder formas de imposición de un 
solo proyecto de vida o de una sola forma de racionalidad; no existe algo así como un espacio objetivo y neutral ajeno a cualquier tradición religiosa o cultural.

$\mathrm{Si}$ bien es cierto que los conflictos interculturales ocurren en aquello que resulta ser más fundamental, esto es, las nociones básicas y conceptos donde yace la fundamentación de las tradiciones religiosas y culturales (Gómez, 2012, p. 106), para señalar en qué consiste una crítica intercultural a la racionalidad postsecular, es necesario explicar qué significa afirmar que existen diversas formas de racionalidad, para así aclarar el proyecto de la crítica intercultural, que es establecer las condiciones de posibilidad de una sociedad postsecular que no sea ciega al pluralismo ni a la heterogeneidad de racionalidades.

Siguiendo con el análisis presentado por Gómez en Interculturality, rationality and dialogue: In search for intercultural argumentative criteria for Latin America (2012), hay tres sentidos en los que se puede comprender lo que significa la existencia de formas de racionalidad heterogéneas: 1) como la relatividad cultural de los principios y las reglas formales de la lógica, 2) como la pluralidad de formas de concebir la realidad, de paradigmas o formas de interpretar la existencia y 3) como la existencia de distintos patrones de razonamiento capaces de ofrecer explicaciones y justificaciones de las prácticas y creencias (pp. 79-80).

Si bien la primera forma de explicar lo que significa la existencia de racionalidades heterogéneas resulta útil para entender cómo los mismos principios lógicos pueden ser usados de manera distinta, al mismo tiempo puede conducir a una interpretación de los diferentes sistemas lógicos como inconmensurables y, por ende, a una lectura de la inconmensurabilidad entre diferentes culturas. Esta inconmensurabilidad podría ser utilizada como una excusa para apelar a la diferencia radical y, por tanto, llevaría a la imposibilidad de entender al otro por cuenta de esta ausencia de un suelo común. Así que, si se entiende la existencia de la heterogeneidad de racionalidades desde la lógica formal, difícilmente puede pensarse en escenarios donde el encuentro intercultural pueda conducir hacia una interacción dialógica. Por eso, vale la pena caracterizar la existencia de racionalidades heterogéneas a partir de los otros dos sentidos presentados por Gómez, pues ambos dejan el camino abierto hacia la posibilidad de emprender un diálogo intercultural donde el encuentro con un otro diferente permita instaurar escenarios en los que el intercambio de razones entre miembros de tradiciones o culturas distintas sea posible.

Sin embargo, entender la existencia de racionalidades heterogéneas, como el encuentro de visiones de mundo que se valen de distintos patrones de razonamiento para argumentar a favor de su proyecto de vida, también podría conducir a una interpretación que intentara responder a esa situación de encuentro entre racionalidades a través de la imposición de ciertos estándares y patrones de una forma de racionalidad sobre otra. Este tipo de exigencias de traducción de un lenguaje religioso a un lenguaje neutral o secular, el cual fue criticado anteriormente a la postura de Habermas, resulta 
desacertado, ya que demandar la traducción a un sistema supuestamente "neutral" es una forma de universalización ilegítima de ciertas formas de razonamiento propias de una sola cultura o tradición, según la cual existe algo así como una razón universal que es capaz de capturar la pluralidad de voces de esas racionalidades heterogéneas, para así integrarlas en la unidad de esta razón universal.

Si bien la postura de Habermas no es tan ingenua como para proponer la imposición de una sola forma de racionalidad en los casos de conflictos argumentativos entre culturas, pues su noción de racionalidad la piensa desde el punto de vista de los criterios propios de las prácticas argumentativas, más que en una noción teórica de razón previa a su uso en la práctica, y lo hace precisamente con el propósito de evitar la posibilidad en el uso de la razón de la intimidación directa al otro y la invalidación de sus puntos de vista; en casos de conflicto intercultural, plantear el uso de estos criterios suscita nuevos interrogantes. Por ejemplo, ¿cómo saber cuándo un aporte argumentativo es relevante o no al diálogo? ¿Cómo garantizar que hay igualdad en el ejercicio de las facultades de comunicación? ¿Cómo determinar que los participantes creen lo que dicen? ¿Cómo evitar el uso de cualquier tipo de coacción directa, pero, sobre todo, indirecta en el intercambio de razones?

Indirectamente, este es el tipo de interrogantes que han ocupado a los autores del así llamado diálogo intercultural, entendido como una "alternativa de comunicación e intercambio entre culturas y tradiciones religiosas cuyos horizontes complejos y ambivalentes están cargados por contradicciones y conflictos internos” (Fornet-Betancourt, 2000). El diálogo intercultural se plantea, entonces, la necesidad de instaurar un ejercicio filosófico que evite los extremos de las posiciones universalistas y relativistas y, al hacerlo, hace énfasis en la importancia de la dimensión argumentativa, pero, sobre todo, en una dimensión hermenéutica orientada por un interés recíproco de comunicación, con miras a establecer dialógicamente reglas que favorezcan el entendimiento entre miembros de diversas culturas y tradiciones (Wimmer, 2000). La dimensión argumentativa permite analizar cómo en un diálogo intercultural se intercambian las razones que sustentan las posiciones de las partes, pero la hermenéutica, además, muestra cómo esas posiciones argumentativas se van construyendo y aclarando a medida que el diálogo mismo ocurre.

Teniendo en mente la importancia tanto de la dimensión hermenéutica como de la argumentativa, el objetivo del ejercicio filosófico intercultural debe ser el de lograr una articulación que reconozca que cada cultura o tradición religiosa, en cuanto visión de mundo, tiene algo por aportarles a las otras. Panikkar (2000) se toma en serio la labor de pensar en cómo fundamentar un proyecto de filosofía intercultural, alejándose de los intentos de traducción planteados por autores como Habermas. Panikkar afirma que una defensa al pluralismo no implica cortar las posibles comunicaciones entre culturas ni mucho menos reducirlas a un común denominador de una razón única. Es aquí donde surge lo que Panikkar ha llamado una "hermenéutica diatópica", la cual invita, no a hacer 
juicios comparativos, sino más bien a reconocer que todo ejercicio de comprensión de una cultura distinta de la propia implica aprender su lenguaje para así saber leer y conocer los pretextos que la han hecho posible. Esta hermenéutica invita a aprender el lenguaje del otro, para entrar en su cultura y ser capaz de entenderlo en sus propios términos.

Si bien es cierto que en las actuales sociedades pluralistas el encuentro de racionalidades heterogéneas ha llevado al surgimiento de conflictos interculturales cuya solución descansa en la instauración de espacios de diálogo intercultural, en ellos la dimensión argumentativa ha sido convencionalmente la manera como se despliega una posible solución de estos conflictos, ya que las partes del diálogo protagonizan un intercambio de razones con un fin comunicativo. Sin embargo, por cuanto se trata de un diálogo de carácter intercultural, la dimensión argumentativa resulta ser insuficiente con respecto a que no ofrece los lineamientos necesarios para entender aquellas razones justificadas por una racionalidad distinta de la propia. Es aquí donde el diálogo intercultural, siguiendo a Pannikar, necesita de una dimensión hermenéutica que evidencie cómo entender el carácter situado de las razones que ofrecen los involucrados en este diálogo y, al hacerlo, ayudar a instaurar espacios de comprensión intercultural encaminados hacia la solución, igualmente intercultural, de los conflictos ocasionados por el encuentro de formas de racionalidad heterogéneas.

En los conflictos interculturales, ocurre algo similar a aquello que tiene lugar cuando el intérprete se encuentra con un texto: hay una experiencia de choque (Gadamer, 1977, p. 335) ocasionada por el encuentro con otro cuyo background cosmovisional distinto del propio y, por eso, sus razones pueden entrar en conflicto con las mías. Sin embargo, a diferencia de los textos, se presupone que los participantes de un diálogo intercultural están capacitados para responder y objetar aquellas críticas o preguntas formuladas por la otra parte.

Desde este panorama, la dimensión hermenéutica del diálogo intercultural señala la importancia de que, si bien cada quien comprende desde su propio horizonte de precomprensión, esto es, desde su propia tradición, se debe estar abierto a escuchar aquello que el otro tiene por decir. Pero esta apertura va más allá de un ejercicio de escucha, pues implica poner la opinión del otro en alguna clase de relación con el conjunto de las opiniones propias (p. 336). Y lo que ocurre en un diálogo intercultural es que las opiniones o, más bien, las posiciones argumentativas ofrecidas por las partes no son estáticas, ya que se van construyendo y clarificando en la medida en la que el diálogo mismo va desarrollándose.

Siendo así, comprender a otro diferente de mi implica estar dispuesto a dejar que el otro hable y que yo sea capaz, no de presuponer la existencia de un espacio neutral en el cual pueda tener lugar algo así como un acuerdo, sino más bien reconocer que ese otro tiene algo por aportarle tanto al diálogo mismo como a mi propia autocomprensión. Una crítica intercultural con atención sobre la dimensión hermenéutica permite 
evidenciar cómo en el encuentro dialógico de racionalidades heterogéneas puede haber una ampliación de los procesos de comprensión de cada una de las partes involucradas en los diálogos que acaecen en las actuales sociedades pluralistas.

El "resurgimiento" de las religiones en las sociedades occidentales, que más que un resurgimiento fáctico es la descripción de un estado de las sociedades contemporáneas en el que las decisiones públicas deben ajustarse al hecho de la existencia continua de comunidades religiosas en medio de instituciones y valores seculares, es solo uno más de los síntomas de sociedades crecientemente pluralistas, en las cuales estar con el otro y tomar decisiones con él se convierte en un problema político de primer orden. Habermas ha pretendido responder a este interrogante con su propuesta descriptivonormativa de las sociedades postseculares. Propuesta que es valiosa en cuanto no se resigna a la inconmensurabilidad y el conflicto, sino que ofrece criterios con los cuales lograr la comprensión, en este caso, entre ciudadanos religiosos y seculares. Empero, como señalamos a través de las críticas de Cooke y Rummens sobre los límites que este pone a los ciudadanos religiosos desde el punto de vista de las exigencias de traducción de sus argumentos y creencias a un lenguaje neutro y a través de los escenarios a los que se refiere el diálogo intercultural, en autores como Gómez o Pannikar, donde las racionalidades paralelas se enfrentan en conflictos fundamentales sobre comprensiones distintas de mundo, parece que el mismo Habermas no ha sacado plenamente las consecuencias de lo que el pluralismo de las sociedades contemporáneas supone, al intentar mantener un ámbito neutral del intercambio argumentativo, el cual exige la traducción de las exigencias y creencias de todas las partes. Pensar no contra Habermas, sino gracias a él sobre cómo responder al pluralismo, supone exigirnos aún más. Supone que profundicemos analíticamente sobre cómo responder al permanente desafío hermenéutico de entender al otro, cuya forma de ser, pensar o creer nos desborda y desconcierta.

\section{Referencias}

Audi, R. y Wolterstorff, N. (1997). Religion in the public square: The place of religious convictions in political debate. Lanham: Rowman \& Littlefield Publishers.

Austin, J. L. (1998a). Conferencia I. En Cómo hacer cosas con palabras (trad. G. R. Carrió y E. A. Rabossi, pp. 41-54). Barcelona: Paidós.

Austin, J. L. (1998b). Conferencia III. En Cómo hacer cosas con palabras (trad. G. R. Carrió y E. A. Rabossi, pp. 41-54). Barcelona: Paidós.

Austin, J. L. (1998c). Conferencia IX. En Cómo hacer cosas con palabras (trad. G. R. Carrió y E. A. Rabossi, pp. 41-54). Barcelona: Paidós.

Berger, P. (1999). The desecularization of the world: Resurgent religion and world politics. Washington DC: Wm. B. Eerdmans Publishing Company. 
Cooke, M. (2006). Salvaging and secularizing the semantic contents of religion: The limitations of Habermas's postmetaphysical proposal. International Journal for Philosophy of Religion, 6o(1-3), 187-207.

Cooke, M. (2007). A secular state for a postsecular society? Postmetaphysical political theory and the place of religion. Constellations, 14(2), 224-238.

Fornet-Betancourt, R. (2000). Supuestos filosóficos del diálogo intercultural. Polylog: Foro para filosofía intercultural, 1. Recuperado de http://red.pucp.edu.pe/ridei/ wp-content/uploads/biblioteca/o81017.pdf

Gadamer, H.-G. (1977). La historicidad de la comprensión como principio hermenéutico. En Verdad y método (pp. 331-377). Salamanca: Sígueme.

Gómez, C. M. (2012). Interculturality, rationality and dialogue: In search for intercultural argumentative criteria for Latin America. Berlín: Echter Verlag.

Gómez, C. M. (2014). Las condiciones postseculares de la creencia religiosa. En C. M. Gómez (ed.), La religión en la sociedad postsecular: transformación y relocalización de lo religioso en la modernidad tardía (pp. 17-64). Bogotá: Universidad del Rosario.

Habermas, J. (1988). Motivos del pensamiento posmetafísico. En Pensamiento posmetafísico (pp. 38-63). Madrid: Taurus.

Habermas, J. (1991) La inclusión del otro. Barcelona: Paidós.

Habermas, J. (2006a). Introducción. En Entre naturalismo y religión (pp. 9-18). Barcelona: Paidós.

Habermas, J. (2006b). Pluralismo religioso y solidaridad ciudadana. En Entre naturalismo y religión (pp. 107-158). Barcelona: Paidós.

Habermas, J. (2008). Apostillas sobre una sociedad postsecular. Revista Colombiana de Sociología, 31, 169-183.

Habermas, J. (2010a). A postsecular world society? On the philosophical significance of postsecular consciousness and the multicultural world society. Social Science Research Council. Recuperado de https://mronline.org/2010/03/21/apostsecular-world-society-on-the-philosophical-significance-of-postsecularconsciousness-and-the-multicultural-world-society/

Habermas, J. (2010b). Introducción. En Teoría de la acción comunicativa (pp. 23-182). Madrid: Taurus.

Mardones, J. M. (2005) La transformación de la religión: cambio en lo sagrado y cristianismo. Madrid: PPC. 
Panikkar, R. (2000). Religión, filosofía y cultura. Polylog: Foro para filosofía intercultural, 1. Recuperado de http://them.polylog.org/1/fpr-es.htm

Rummers, S. (2010). The semantic potential of religious arguments: A deliberative model of postsecular public sphere. Social Theory and Practice, 36(3), 385-408.

Schmidt, T. (2014). Hacia un pluralismo razonable: la secularización y el futuro de la religión. En C. M. Gómez (ed.), La religión en la sociedad postsecular (pp. 113131). Bogotá: Universidad del Rosario.

Wimmer, F. M. (2000). Tesis, condiciones y tareas de una filosofía orientada interculturalmente. Polylog: Foro para filosofía intercultural, 1. Recuperado de https:// them.polylog.org/1/fwf-es.htm 
